\title{
POR QUE FALAR EM PEDAGOGIA DO JOGO?*
}

\author{
João Carlos Martins Bressan ${ }^{1}$
}

\section{Preâmbulo}

O título que ilustra o texto a que me dedico escrever faz referência ao âmbito escolar, notadamente ao conteúdo esporte e aos desafios latentes para seu ensino em tempos contemporâneos. Esses desafios são oriundos de questionamentos essenciais que têm caminhado pari passu com a humanidade ao longo do tempo: o que ensinar? Para quem ensinar? Como ensinar? Quando ensinar? Para que ensinar? Essas indagações encontram esteio em questões basilares que guardam relação com os processos de ensino e aprendizagem, os quais são responsáveis pela continuidade e ressignificação do conhecimento acumulado ao longo do tempo por diferentes sociedades, principalmente, na dimensão cultural.

A educação institucionalizada enquanto espaço favorável para a formação humana tem lidado com esse cenário e a Educação Física, por meio de seus representantes, tem expressado críticas ao conteúdo esporte em âmbito escolar; e, apesar de diferentes posicionamentos sobre tal, há concordância no tocante à necessidade de tratá-lo pedagogicamente (LOVISOLO, 2009). Ao discorrer sobre esporte, cabe salientar que, em seu caráter educacional, ele é um dos fenômenos mais importantes da atualidade (BARBIERI, 2001; PAES, 2006), o que, por sua vez, tem gerado grande impacto na formação humana em diferentes momentos e espaços. Nesse sentido, Rúbio (2008, p. 20) referenciando Parlebás (1988) alerta que "o esporte não é bom, nem ruim. O esporte é aquilo que fazemos dele. Diante dessa afirmação, sou levada a entender que o esporte pode levar a dois polos diametralmente opostos: a inclusão e a exclusão."

Em referência aos usos contemporâneos desse fenômeno, leia-se esporte, e como esses processos têm sido pensados no campo da pedagogia, enumeram-se algumas indagações, entre as quais: Como a pedagogia tem se orientado em resposta a essa conjuntura? Como a teoria do

* 10.29388/978-65-86678-46-8-0-f.117-128

${ }^{1}$ Professor assistente do curso de Educação Física da Universidade do Estado de Mato Grosso (UNEMAT). Mestre em Educação pela Universidade Federal de Mato Grosso (UFMT) e Doutorando em Desenvolvimento Humano e Tecnologias pela Universidade Estadual Paulista Júlio de Mesquita (UNESP). Coordenador do Laboratório de Estudos em Pedagogia do Jogo (LEPEJ). E-mail: bressan@,unemat.br 
jogo, ao se fundir ao conceito de pedagogia, tem se apresentado enquanto relevante, para os processos formativos? Caminha-se para um ponto de mutação ${ }^{2}$ em direção a um novo paradigma que ressignifica os espaços escolares para aprendizagem do conteúdo esportivo?

Frente aos questionamentos apresentados, o presente texto está organizado em três tópicos, quais sejam: a) Delimitar o conceito de pedagogia que sustentará as reflexões; b) Evidenciar breve conceituação sobre a teoria do jogo; c) Situar a Pedagogia do Jogo enquanto vetor de aproximação do conteúdo esporte, da epistemologia da prática do professor e do ambiente escolar, e, por fim, apresentam-se reflexões acerca do ensino do esporte em ambiente escolar, considerando a Pedagogia do Jogo e suas possibilidades.

\section{Da noção ao conceito de pedagogia(s)}

A noção ampla de pedagogia na epistemologia da palavra vem da junção de dois termos do grego antigo, paídos cujo significado se assenta em criança e agodé que corresponde à condução. Para Ghiraldelli (1987), quando essas palavras foram adaptadas para o português, formou-se a palavra pedagogia. $\mathrm{O}$ autor complementa que mormente a função era ocupada por um serviçal ou escravo, portanto, não necessariamente era culto, sua função primordial era a condução pelos caminhos até o espaço de ensino.

Em tempos ditos pós-modernos as marcas da origem da noção de pedagogia aparentam ainda estar em evidência, sobremaneira quando se elencam, prioritariamente, os conteúdos a serem ensinados sem haver atenção para as limitações de quem os ensina (GHIRALDELLI, 1987). E, talvez, esteja nessa perspectiva a herança epistêmica que se carrega, a medida em que, pela ótica docente, os conteúdos têm suplantado, em nível de importância, as capacidades de como possibilitá-los nos espaços escolares.

Ao atentar-se para a perspectiva conceitual, Libâneo (2010, p. 19) esclarece que: "A pedagogia ocupa-se das tarefas de formação humana em contextos determinados por marcos espaciais e temporais." Assim, atribui o sentido de atividade à pedagogia, mas não se restringe a isso, ela se tornou um conceito responsável pela educação (GHIRALDELLI,

${ }^{2}$ Ver Fritjof Capra. O ponto de Mutação: A Ciência, a Sociedade e a Cultura emergente. São Paulo, Cultrix, 1982.

${ }^{3}$ Referência ao livro: “O que é Pedagogia?” de Paulo Guiraldelli Junior. Brasiliense, São Paulo, 1987. 
1987). Nessa esteira de reflexões, Gauthier (1998, p. 136) anota que, no plano conceitual, “[...] é mais pertinente conceber a pedagogia como englobando tudo o que diz respeito aos comportamentos do professor visando a instruir e a educar os alunos [...]". Desse modo, a educação se preenche do sentido de ser o objeto de estudo da pedagogia e a esse respeito, Libâneo (2010, p. 19) enfatiza que:

[...] A investigação do seu objeto, a educação, implica em considerá-lo como uma realidade em mudança. A realidade atual mostra um mundo ao mesmo tempo homogêneo e heterogêneo, num processo de globalização e individualização, afetando sentidos e significados de indivíduos e grupo, criando múltiplas culturas, múltiplas relações, múltiplos sujeitos. Se, de um lado, a pedagogia centra suas preocupações na explicitação de seu objeto dirigindose ao esclarecimento intencional do fenômeno do qual se ocupa, por outro, esse objeto requer ser pensado em sua complexidade.

A pedagogia, na condição de conceito, é passível de várias definições; e, na guisa de alcançar essas diferentes facetas, aglutina-se a doutrinas e teorias filosóficas que buscam compreendê-la à luz de suas sustentações epistemológicas. Apropria-se, para as reflexões aqui propostas, da perspectiva teórica em detrimento da doutrinária, buscando aproximações com a teoria da complexidade que, supostamente, melhor sustenta as relações buscadas neste texto; notadamente em relação ao conceito do jogo e sua fusão com o conceito de pedagogia.

\section{O jogo}

Buscar a definição e contextualização do fenômeno "jogo" não se caracteriza como uma tarefa simples. Ao longo da história da humanidade, diferentes personalidades, oriundas dos mais distintos campos do conhecimento, aventuraram-se em tal empreitada, o que permitiu considerável acúmulo de conhecimento sobre o tema, conforme assinala Carneiro (2012, p. 34) "O fenômeno jogo tem sido alvo de investigações em áreas diferentes do conhecimento [...]". Sendo, portanto, “[...] consenso entre pesquisadores e estudiosos as dificuldades que cerceiam a compreensão deste fenômeno [...]" (CARNEIRO, 2012, p. 34), essa assertiva é chancelada por Brougère (1998) ao enfatizar a não disponibilidade de transparência e clareza do conceito, como se já estivesse construído. O 
autor reafirma que estamos a lidar com uma noção aberta, polissêmica e de sazonal ambiguidade.

Não serão expressas, obviamente, neste capítulo, as tentativas de abarcar essas diferentes áreas do conhecimento que já se pronunciaram em relação à teoria, tanto pelo objetivo de tal escrita, como também pelos limites existentes em tal compilação ${ }^{4}$, pois, como advoga Carneiro (2017, p. 29), “A palavra jogo carrega consigo uma forte carga semântica, e suas manifestações possuem aspectos subjetivos. Essas características acarretam muitas interpretações equivocadas sobre o fenômeno." Para evitar tal cenário, o que aqui se apresenta, corresponde a uma singela introdução acerca do tema, com vistas a possibilitar caminhos para pensar o mote que orientará as reflexões aqui expressas.

Delimitado isso, busca-se evidenciar o jogo em uma perspectiva complexa que, conforme Carneiro (2017, p. 30), “[...] pode ser facilmente percebida quando se observam as diferentes áreas, sejam das ciências humanas, sejam das ciências exatas, que se propuseram a desenvolver investigações, tomando-o como objeto de conhecimento". Essa complexidade apresentada assenta-se em detrimento do simplismo que fragmenta o fenômeno, gerando não sua compreensão, mas uma ilusão (FREIRE, 2001). Tal concepção encontra azo na assertiva de que complexo não é simplesmente complicado, mas sim, permeado por um infindável número de interações e interferências em um grande número de unidades (MORIN, 2000).

Compreender o jogo sob a égide do pensamento complexo, implica romper com o mecanicismo e o cartesianismo e caminhar rumo a uma visão ecológica e sistêmica ${ }^{5}$. Nas palavras de Scaglia (2003, p. 54):

\footnotetext{
${ }^{4}$ Sugiro a leitura dos livros: "O jogo na Educação Física: As concepções dos professores”. São Paulo, Phorte, 2012 e também "Por uma memória do jogo: A presença do jogo na infância das décadas de 20 e 30" Curitiba, Appris. 2017. Ambos de autoria de Kleber Tuxen Carneiro.

5 "Os ecológicos procuram aproximar o pensamento da ação, valorizam as possibilida des de ações (affordances) que se estabelecem entre o sujeito (jogador) e todo o ambiente (seu entorno, que inclui os demais jogadores, suas intencionalidades, questões físicas, estruturais e funcionais do jogo)." (SCAGLIA; REVERDITO, 2016, p. 59). Para aprofundamento em relação aos conceitos de ecológico e sistêmico ver: CAPRA, F.; LUISI, P. L. A visão sistêmica da vida: Uma concepção unificada e suas implicações filosóficas, políticas, sociais e econômicas. São Paulo: Cultrix, 2014.
} 
[...] o pensamento complexo pode ser considerado um paradigma emergente que nasce no bojo de revolucionárias ideias decorrentes do imbricamento de várias áreas do conhecimento, as quais buscam definitivamente romper com o paradigma mecânico/cartesiano e seus dualismos positivistas, buscando entender o mundo a partir de uma visão ecológica e sistêmica.

O jogo é polissêmico - passível de diferentes significados e conceituações - e também abstrato, pois "ele se concretiza por intermédio de suas manifestações - jogo/brincadeira, jogo/esporte, jogo/dança, jogo/lutas... [...] (SCAGLIA, 2003, p. 60). Assim, o jogo não existe, senão quando expresso por diferentes práticas corporais. $\mathrm{O}$ ato de jogar provoca arrebatamento ao universo do Senhor do jogo $0^{6}$ quando, então, seu praticante, inebriado por um espaço-tempo particular, é envolto de um ambiente potencial de aprendizagem. A esse respeito, Carneiro (2017, p. 113) anota que:

Tal expressão denota uma condição de arrebatamento produzida pelo jogo. Como no ambiente de jogo existe "liberdade", o jogador é o Ser do jogo, tem poder, porém sua liberdade e poder são relativos. Tal relatividade torna-se ainda mais evidente no momento que entra em cena a figura do "Senhor do jogo". Ele é o legislador, o ente que controla e restringe o jogo de forma subjetiva, como um sedutor que embala o jogador através do ritmo harmônico de seu jogo. É dessa forma que o "Senhor do jogo", o sujeito metafórico do jogo, joga com o jogador.

O jogo pode ser estudado considerando-o objeto, conteúdo e também metodologia (FREIRE, SCAGLIA, 2003). Quando observado pela ótica de conteúdo, ele em si é o objeto de investigação; já na perspectiva de metodologia, há um esforço para acomodá-lo enquanto facilitador de processos de ensino, sendo, portanto, ferramenta pedagógica, porém o desafio colocado nesse formato está em não o descaracterizar pelo excesso de instrumentalização.

No que concerne ao jogo e sua relação com o ensino do esporte, Scaglia e Reverdito (2016, p. 46) escrevem que: "São muitas as vertentes, escolas e autores ao redor do mundo que intensificam seus estudos, pesquisas e propostas didático-metodológicas para diferentes ambientes for-

\footnotetext{
${ }^{6}$ Expressão utilizada por João Batista Freire em seu livro: O jogo: entre o riso e o choro (2002)
} 
mativos [...]". E, no âmago dessas novas tendências, todas "convergem para uma mesma direção, que é diametralmente oposta à abordagem tradicional em toda sua raiz epistemológica" (SCAGLIA; REVERDITO, 2016, p. 47). Essas novas tendências/perspectivas "valorizam impreterivelmente o fenômeno jogo, evidenciando a necessidade e urgência de valorizar o contexto do jogo nos momentos de aprendizagem [...]" (47).

Com vistas a promover um encadeamento de reflexões, observase o ambiente de jogo enquanto legitimador de um processo de ensino, sendo, portanto, essência primordial à aprendizagem, notadamente nos processos formativos que envolvem os esportes, os quais, por sua vez, são a materialização do jogo. Mais do que isso, o jogo tem se figurado como vetor possível para a ressignificação da epistemologia da prática docente $^{7}$ e sua relação com o esporte em ambiente formativo escolar, nesse bojo, a pedagogia do jogo apresenta-se como um caminho.

\section{A pedagogia do jogo e o ato de ensinar}

O conceito de Pedagogia do Jogo não é inédito, notadamente ao ser observado sob pressupostos metodológicos para o ensino dos esportes, nesse contexto há um consenso que as novas tendências em Pedagogia do Esporte têm lançado mão do jogo enquanto elemento pedagógico já há algumas décadas. (SCAGLIA; REVERDITO, 2016; SCAGLIA, 2017). Em outra perspectiva, quando observado em âmbito escolar, considerando a prática pedagógica do professor, surgem tensões que conclamam reflexões que considerem a epistemologia da prática docente, e nessa esteira, as produções científicas sobre a Pedagogia do Jogo ainda não foram suficientemente criticadas.

O processo de ensino, observado unilateralmente pela ótica do ato de ensinar, é uma prática fundamental da atividade humana, tanto quanto o trabalho, a técnica, a arte ou a política (TARDIFF, 2008). Essa prática pedagógica é embasada em escolhas que ocorrem sob a dimensão intrínseca de quem ensina (preferências ideológicas, concepções e cren-

\footnotetext{
7 Utilizo o conceito em uma perspectiva que considera a função professoral adequada ao ambiente de trabalho para o qual está designado. Nas palavras de Gamboa (2008, p. 162) "A expressão epistemologia da prática se refere à análise dos significados da prática, da sua construção histórica e da sua relação com outros conceitos, tais como teoria e práxis."
} 
ças), as quais, por sua vez, são mutáveis e, constantemente, tornam-se alinhavadas ou contraditórias aos espaços em que atuam pedagogicamente - dimensão extrínseca -, que são regidos por uma estrutura política e pedagógica normatizada por orientações parametrizadas de currículo, além de legislação regulamentária.

Como exemplo, pode-se citar uma instituição escolar brasileira que se encontra orientada legalmente pela Lei de Diretrizes e Bases da Educação Nacional (LDB, Lei 9394/96), subsidiada pedagógica e metodologicamente a partir de 2017-2018 pela Base Nacional Comum Curricular (BNCC), também pelas Diretrizes Curriculares Estaduais e por normatizações municipais. A escola ainda possui um projeto político pedagógico (PPP) que rege a atuação de todos os sujeitos que ocupam seu espaço. Essas leis, parâmetros, orientações e normas devem, em tese, não serem contraditórias, mas sim complementares, adequando-se aos regionalismos e peculiaridades de cada lócus. É salutar recordar que se considerou, aqui, apenas um exemplo de instituição formativa (escola), localizada dentro da perspectiva da educação formal; tendo, ainda, as dimensões de educação informal e não formal, apresentando, igualmente, diferentes espaços formativos, conforme assinala Libâneo (1998).

Situado o ambiente formativo, retoma-se o conceito de complexo exacerbado por Morin (2001, p. 38) em que "Complexus significa o que foi tecido junto; de fato, há complexidade quando elementos diferentes são inseparáveis constitutivos do todo [...]". O todo aqui elencado é constituído do ambiente pedagógico escolar propriamente dito, que encontra diferentes possibilidades em distintos contextos, sendo esses elementos geradores da necessidade de um condutor (legítimo) "[...] um tecido interdependente, interativo e inter-retroativo entre o objeto de conhecimento e seu contexto, as partes e o todo, o todo e as partes, as partes entre si." (MORIN, 2001, p. 38).

Portanto, para o ensino do esporte em âmbito escolar, emana a necessidade de uma pedagogia que esteja calcada na complexidade, que seja sistêmica e ecológica; e que, concomitante, seja também passível, em sua origem, de orientar-se sob os preceitos da epistemologia da prática professoral, que visa encontrar esteio na tarefa de ensinar de modo a considerar a formação humana sob essa ótica, para que as gerações que frequentam esses espaços possam viver, problematizar e melhorar o contexto social de que fazem parte. Para tanto, os que frequentam os bancos das escolas precisam ser sensibilizados sobre esse paradigma (complexi- 
dade) que orienta o mundo em que se vive. Essa demanda permite elencar o jogo enquanto o "tecido" que conecta o objeto de conhecimento (esporte) e seu contexto (espaços de ensino).

O jogo, por sua complexidade, é uma possibilidade conectiva de pedagogia acertada para as tarefas e desafios em que a escola precisa se fazer presente, e o esporte (e não somente ele) demonstra-se como um conteúdo alvissareiro para somar a esse propósito. Assim, as leituras e reflexões acerca do tema, orientam este pesquisador na direção de conceber que a educação formal, que acredite no potencial formativo do esporte e que se preze a fazer sentido na vida dos escolares, precisa considerar, como ponto de partida, a epistemologia da prática docente em uma pedagogia que esteja alinhada aos preceitos de uma escola republica$\mathrm{na}^{8}$, orientada para formação crítica e libertadora ${ }^{9}$ e que observe essas demandas sistêmicas pelo paradigma da complexidade. Enfim, a Pedagogia do Jogo tem convergido para ser esse vetor.

\section{Considerações fỉnais}

A aventura da escrita do presente capítulo permitiu tecer singelas reflexões sobre a Pedagogia do Jogo enquanto possibilidade para o ensino do esporte em ambiente escolar. $\mathrm{O}$ ato de jogar gera um ambiente propício para a aprendizagem, mas o papel do professor é essencial, pois o estado de jogo é dinâmico e prover a permanência efetiva de escolares nesse estado, é vital para o sucesso da empreitada. Para Scaglia, Reverdito e Galatti (2013) o contexto determina o que é ou não jogo, o que, consequentemente, permite ou não o engajamento e o ambiente de jogo, que pode ou não gerar o estado de jogo que se relaciona com o ambiente de aprendizagem; essas situações são preenchidas pelo impulso lúdico do jogador delimitado pelo êxtase e frivolidade (HUIZINGA, 1999) e pela maneira de jogar ludus e paídia (CAILLOIS, 1990). Para ilustrar essa dinâmica, apresenta-se a figura a seguir.

\footnotetext{
${ }^{8}$ Utiliza-se o conceito com base em González e Fensterseifer (2009) que entendem a escola enquanto um organismo político de um estado com vistas ao interesse público (comum).

9 Baseado em Paulo Freire: Educação como prática da Liberdade. Paz e Terra. Rio de Janeiro. 1967
} 
Figura 1. Circunstância do Jogo: os polos antagônicos e reguladores

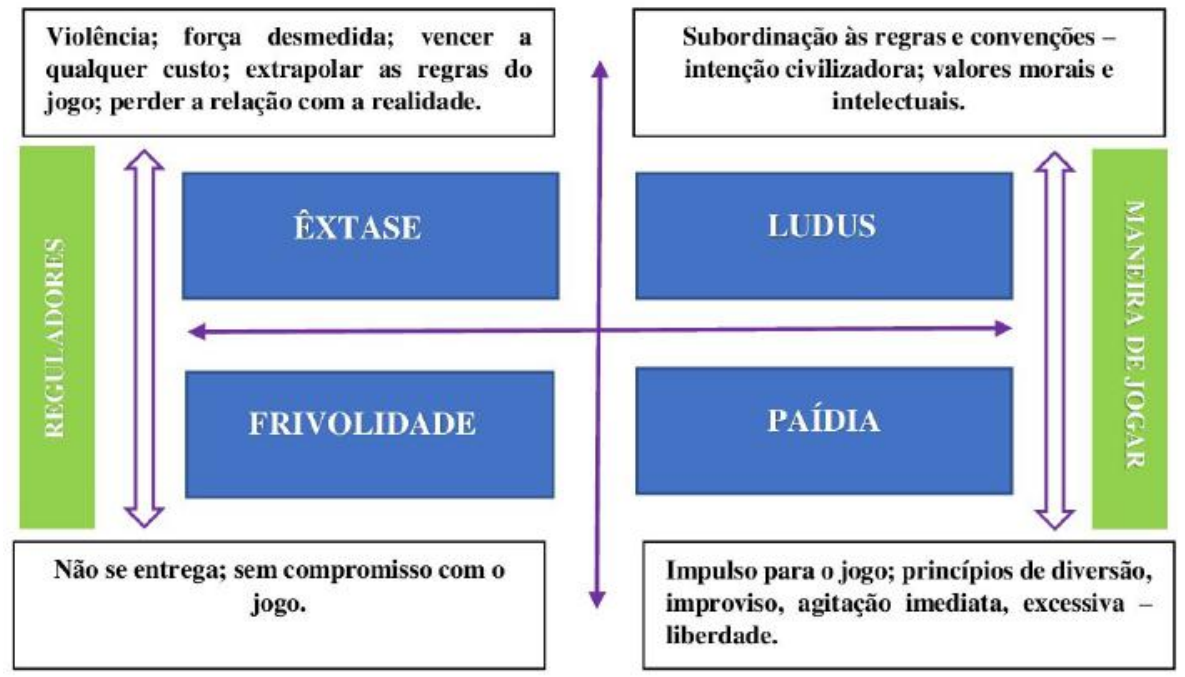

Fonte: Reverdito $(2011,2019)^{10}$ embasado em Caillois (1990) e Huizinga (1999).

Aventurar-se em uma Pedagogia do Jogo é compreender que "[...] ordem e desordem, certezas e incertezas, confusão e clareza coabitam o mesmo sistema [...]" (SCAGLIA; REVERDITO, 2016, p. 50). Os estímulos pedagógicos precisam ser orientados sob a compreensão de que existe uma tênue linha que separa o que é ambiente de aprendizagem preenchido pela liberdade de expressão do impulso lúdico; e, por outro lado, o que é um outro ambiente formativo orientado pela obrigatoriedade.

É preciso favorecer a manutenção de uma zona lúdica de aprendizagem que ocorre, segundo Winnicott (1975, p. 93), “[...] no excitante entrelaçamento da subjetividade e da observação objetiva, e numa área intermediária entre a realidade interna do indivíduo e a realidade compartilhada do mundo externo aos indivíduos". É na materialização do jogo por meio do esporte (e não somente por ele) que seres humanos conseguem fruir sua liberdade de criação, "como se houvesse um lugar de convergência entre o inteligível e o sensível” (BRESSAN; CARNEIRO, 2018, p. 33).

\footnotetext{
${ }^{10}$ Em 2011, o autor apresentou o marco teórico em sua dissertação; em 2019, expôs o organograma em uma palestra, ofertada no Centro Interdisciplinar de Pesquisas em Esporte e Exercício Físico da Universidade do Estado de Mato Grosso (CIPEEF/UNEMAT) em Cáceres/MT.
} 
Por fim, é imperativo afirmar a necessidade de compreender a escola como um espaço de emergência da corresponsabilidade formativa, a qual é preenchida pelo anseio da formação cidadã; ainda, que esse espaço não é uma ilha, portanto, está imerso em meio aos desafios de uma sociedade em transformação. Observado isso, é possível situar essa instituição dentro de uma perspectiva sistêmica e complexa, cuja condição impossibilita avançar por meio de práticas pedagógicas simplistas, fragmentárias e generalistas.

Para o alcance do que se almeja, é preciso romper com modismos e descontinuidades, extasiando a dimensão subjetiva do educador, em que só o conhecimento e sua aplicação são capazes de acessar; e, a partir disso, sustentar esse ideário na teimosia de práticas pedagógicas transformadoras (na lida profissional diária) e em saudáveis debates em outras dimensões e contextos da profissão. A Pedagogia do Jogo é urgente! À medida que considera os professores e professoras, a escola, e o esporte, sob o prisma de suas essências.

\section{Referências}

BARBIERI, C. A. S. Esporte Educacional: uma possibilidade para restauração do humano no homem. Canoas: ULBRA, 2001.

BRASIL. Ministério de Educação e Cultura. LDB - Lei n 9394/96, de 20 de dezembro de 1996. Estabelece as diretrizes e bases da Educação Nacional. Brasília, DF: MEC, 1996.

. Ministério da Educação. Base Nacional Comum Curricular: educação é a base. Brasília-DF: Ministério da Educação, 2018. Disponível em:

$<$ http://basenacionalcomum.mec.gov.br/images/BNCC EI EF 110518 versaofinal_site.pdf.>. acesso em: 10 jun. 2020.

BRESSAN, J, C. M.; CARNEIRO, K. T. Lúdico na escola (ciclada): do ocaso ao protagonismo. Curitiba: Appris, 2018.

BROUGÈRE, G. Jogo e educação. Porto Alegre, Artes Médicas, 1998.

CAILLOIS, R. Os jogos e os homens. Lisboa: Portugal, 1990.

CAPRA, F. O Ponto de Mutação. São Paulo, Cultrix, 1982.

CAPRA, F.; LUISI, P. L. A visão sistêmica da vida: uma concepção unificada e suas implicações filosóficas, políticas, sociais e econômicas. Trad. Mayra Teruza Eichemberg. São Paulo: Cultrix, 2014.

CARNEIRO, K. T. O jogo na Educação Física: as concepções dos professores. São Paulo: Phorte, 2012. 
Por uma memória do jogo: a presença do jogo na infância das décadas de 20 e 30. Curitiba: Appris, 2017.

FREIRE, J. B. Investigações preliminares sobre o jogo. Campinas: FEFUNICAMP (Tese de livre docência), 2001.

Jogo: entre o riso e o choro. Campinas: Autores Associados, 2002.

FREIRE, J. B., SCAGLIA A. J. Educação como prática corporal. São Paulo: Scipione, 2003.

FREIRE, P. Educação como prática da liberdade. Rio de Janeiro, Paz e Terra, 1967.

GAMBOA S. S. Epistemologia da prática. In: GONZÁLEZ, F. J.; FENSTERSEIFER, P. E. (orgs) Dicionário crítico de Educação Física. $2^{\mathrm{a}}$ ed. rev. Íjui: Unijuí. 2018, p. 161-165.

GAUTHIER, C. et al. Por uma teoria da pedagogia: pesquisas contemporâneas sobre o saber docente. Ijuí: Unijuí, 1998.

GHIRAlDelli, P. O que é pedagogia (Primeiros Passos). Brasiliense. São Paulo, 1987.

GONZÁLEZ, F. J.; FENSTERSEIFER, P. E. Entre o "não mais" e o "ainda não": pensando saídas do não-lugar da ef escolar I. Cadernos de Formação RBCE, p. 9-24, set. 2009.

HUIZINGA, J. Homo Ludens: o jogo como elemento da cultura. Trad. João Paulo Monteiro. São Paulo: Perspectiva, 2007.

LIBÂNEO, J. C. Os significados da educação, modalidades da prática educativa e a organização do sistema educacional: In: Pedagogia e pedagogos, para quê? São Paulo, Cortez, 1998. P.61-96.

. As teorias Pedagógicas Modernas Revisitadas pelo Debate Contemporâneo na Educação. In: LIBÂNEO, J. C.; SANTOS, A. (orgs) Educação na era do conhecimento em rede e transdisciplinaridade. $3^{a}$ ed. revisada. São Paulo, Alínea, 2010.

LOVISOLO, H. Mediação: Esporte de rendimento e esporte da escola. In: STIGGER, M. P.; LOVISOLO, H. (ORGS). Esporte de rendimento e esporte na escola. Campinas: Autores Associados, 2009.

MORIN, E. A Inteligência da Complexidade. 2 ed. São Paulo: Petrópolis, 2000. tez, 2001.

Os sete saberes necessários à educação do futuro. São Paulo: Cor- 
PAES, R. R. Pedagogia do esporte: contextos, evolução e perspectivas. Revista Brasileira de Educação Física e Esporte, São Paulo, v. 20, supl. 5, p. 171, set. 2006. Disponível em: < http://www.usp.br/eef/ xipalops2006/48 Anais_p171.pdf>. Acesso em: 10 jun. 2020.

REVERDITO, R. S. Jogo e desenvolvimento: estudo com crianças de 05 e 06 anos em uma escola privada na cidade de Hortolândia/SP. Dissertação (Mestrado em Educação Física) - Programa de Pós Graduação em Educação Física, Universidade Metodista de Piracicaba, Piracicaba/SP, 2011.

RÚBIO, K. Esporte e juventude: privilégio ou direito? de todos ou dos habilidosos? 11-26. In: ESPINDULA, B. (org.) Políticas de Esporte para juventude: contribuições para o debate. São Paulo, Centro de Estudos e Memória da Juventude (CEMJ), Instituto Pensarte, 2008.

SCAGLIA, J. A. O futebol e os jogos/brincadeiras de bola com os pés: todos semelhantes, todos diferentes. 2003, 164f. Tese (doutorado em Pedagogia do Movimento) Faculdade de Educação Física, Universidade de Campinas, Campinas.

. Pedagogia do Jogo: O processo organizacional dos Jogos Esportivos Coletivos enquanto modelo metodológico para o ensino. Revista Portuguesa de Ciências do Desporto. 2017. 27-38. 10.5628/rpcd.17.S1A.27.

SCAGLIA, A. J.; REVERDITO, R. S.; GALATTI, L. R. Ambiente de jogo e ambiente de aprendizagem no processo de ensino dos jogos esportivos coletivos: desafios no ensino e aprendizagem dos jogos esportivos coletivos: In: NASCIMENTO, J. V.; RAMOS, V.; TAVARES, J. (Org.). Jogos desportivos: formação e investigação. Florianópolis: UDESC, 2013. p. 133-170.

SCAGLIA, A. J.; REVERDITO, R. S. Perspectivas pedagógicas no século XXI. In: NISTA-PICCOLO, V.; MOREIRA, W. W. (Org.). Educação Física e Esporte no Século XXI. Campinas: Papirus, 2016, p. 43-72.

TARDIF, M. Saberes docentes e formação profissional. $9^{\mathrm{a}} \mathrm{ed}$. Petrópolis /RJ: Vozes, 2008.

WINNICOTT, D. W. O brincar e a realidade. Rio de Janeiro: Imago, 1975.

Agradecimentos: Ao Professor Kleber Tuxen Carneiro, docente da Universidade Federal de Lavras (UFLA). A Professora Leila Maira Borré, docente vinculada à Secretaria Estadual de Educação de Mato Grosso (SEDUC/MT). A Professora Karine Silva Bozoki, vinculada ao Centro Interdisciplinar de Pesquisas em Esporte e Exercício Físico da Universidade do Estado de Mato Grosso (CIPEEF/UNEMAT). 